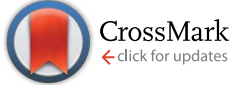

Cite this: RSC Adv., 2017, 7, 5019

\title{
Lipase immobilization on facile synthesized polyaniline-coated silver-functionalized graphene oxide nanocomposites as novel biocatalysts: stability and activity insights $\uparrow$
}

\begin{abstract}
Shamoon Asmat, ${ }^{a}$ Qayyum Husain*a and Ameer Azam
Enzymes perform an essential role in catalysing extensive reactions. Yet, their instability upon repetitive use, as well as their activity inhibition by different solvent remains a cumbersome task. We present here a simple method to immobilize Aspergillus niger lipase (ANL) onto polyaniline-silver functionalized graphene oxide nanocomposites (PANI/Ag/GO), involving the facile synthesis of PANI/Ag/GO and the preparation of ANL@PANI/Ag/GO nanocomposites. Covalent bonding was achieved via glutaraldehyde as a cross linking agent onto these nanocomposites. The resulting ANL(APANI/Ag/GO with a nanoscale dimension has a remarkably high enzymatic activity recovery yield of $88.5 \%$ and immobilization yield upto $94 \%$. The apparent optimum temperature and $\mathrm{pH}$ for ANL@PANI/Ag/GO were higher than those of free ANL. ANL@PANI/Ag/GO exhibited comparatively higher catalytic efficiency and enzyme-substrate affinity. The binding of ANL on PANI/Ag/GO-NCs was confirmed by Fourier transform infrared spectroscopy, transmission electron microscopy, scanning electron microscopy, dynamic light scattering and atomic force microscopy. The metal content was examined by energy-dispersive X-ray spectroscopy. ANL@PANI/Ag/GO biocatalyst retained over $86 \%$ of its initial enzyme activity after 11 repeated uses. ANL@PANI/Ag/GO displayed significantly enhanced solvent tolerance and high thermal stability compared to the free enzyme, it might be due to the increase in enzyme structure rigidity. This remarkable stability and nanobiocatalytic performance in conditions concerning temperature and

solvents, will have a deep impact on the industrial scale up of biocatalytic systems.
\end{abstract}

Received 8th December 2016 Accepted 4th January 2017

DOI: 10.1039/c6ra27926k

www.rsc.org/advances

\section{Introduction}

Efficient and highly selective catalysis by enzymes has steered towards the diverse use of enzymes in food, biomedical assays, detection technologies and industrial processes. ${ }^{1-3}$ Still, further industrial scale application of enzymes is limited due to a number of hindrances such as difficulties in recovery and reuse, high cost and poor operational stability. ${ }^{4-6}$ Immobilization of enzymes can efficiently overcome these hurdles and has been considered as one of the best alternatives to exploit them at large scale. Immobilization techniques includes several methods such as physical entrapment, covalent attachment and adsorption, cross-linking, adsorption followed by cross-linking but from an industrial point of view covalent attachment of an enzyme to a support is perhaps the most significant method

${ }^{a}$ Department of Biochemistry, Faculty of Life Sciences, Aligarh Muslim University, Aligarh-202002, India. E-mail: qayyumbiochem@gmail.com; Tel: +91-9897701792 ${ }^{b}$ Centre of Excellence in Material Sciences (Nanomaterials), Zakir Husain College of Engineering and Technology, Aligarh Muslim University, Aligarh-202002, India

$\dagger$ Electronic supplementary information (ESI) available. See DOI: 10.1039/c6ra27926k of immobilization. Though still simple, effective immobilization techniques and tools demand further exploration., ${ }^{7,8}$

Lipase (triacylglycerol acylhydrolase EC 3.1.1.3) is an inexpensive biocatalyst which is capable of breaking down lipids with wide substrate specificity and high selectivity. ${ }^{9}$ It offers a large number of applications in pharmaceuticals, food stuffs, cosmetics and the conversion of oil into fuel for biodiesel production. ${ }^{\mathbf{1 0 , 1 1}}$ Compared to enzymes from animals or plant sources, enzymes from microbial sources are more beneficial because of their possible high yields, diversity of catalytic activities, convenient production and prompt growth on inexpensive media. ${ }^{12,13}$ Hence, we selected Aspergillus niger lipase (ANL) as our model enzyme for immobilization.

Since the emergence of nanotechnology, great attention has been paid to the synthesis and modifications of nanoparticles with enhanced performance paving the way to plethora of applications in research and industries. ${ }^{\mathbf{1 4 , 1 5}}$ Nanoparticles exhibit remarkable properties such as high surface reaction activity; large surface to volume ratio; strong adsorption capability; ease of surface functionalization and high catalytic efficiency that make them potential candidates to play a vital role in enzyme immobilization and its further applications. ${ }^{\mathbf{1 6}}$ 
Among several nanosupports, graphene and graphene oxide (GO) have been considered as fascinating nanosupports for a variety of biologically active agents leading to novel biocatalysts, drug delivery carriers and biosensors. ${ }^{17,18} \mathrm{GO}$ is oxygenated, hydrophilic layered carbon material of graphene having monolayers of carbon atoms packed into a dense honeycomb lattice comprising epoxide and hydroxyl functional groups on the two available sides and carboxylic moieties at the edges. ${ }^{19}$ Furthermore, it has attracted increased attention owing to its distinctive properties such as large surface area, lightweight, low cytotoxicity, better water-dispersibility, economical to prepare and readily functionalized by chemical reaction for various applications. Hence, combining and stabilizing nanoscale particles on GO surface is possible owing to presence of epoxide, hydroxyl, carboxyl and carbonyl functional groups on the plane. This makes GO-NPs hybrid nanocomposites as important candidates for the investigation of nanocomposites properties and potential applications. ${ }^{20}$ Effectiveness of graphene as nano-filler can be exploited through incorporation of graphene sheets into composite materials. Amongst the various NPs, Ag NPs interact with GO surface through charge-transfer interactions physisorption or electrostatic binding and have attracted much attention due to their prospective applications in medicines, sensors, catalysis, bioengineering, biotechnology and biomaterials areas. ${ }^{21,22}$ Polyaniline (PANI) contains the large benzene ring system which contributes remarkably to the interaction with aromatic compounds via $\pi-\pi$ interaction and is a promising functional coating material due to high environmental stability, low toxicity and ease of synthesis and functionalization properties. ${ }^{23}$

Thus, in the present study, PANI/Ag/GO nanocomposite was prepared, and ANL was successfully immobilized onto PANI/Ag/ GO via the crosslinking method with pentane-1,5-dial modification. Glutaraldehyde was employed as the crosslinking agent to couple enzyme molecules with PANI/Ag/GO-NCs to yield bionanoconjugates with enhanced storage stability, thermostability and reusability. The surface morphology of PANI/Ag/GO and ANL@PANI/Ag/GO has been characterized by transmission electron microscopy (TEM) and scanning electron microscopy (SEM). Thermal behaviour of PANI/Ag/GO has been investigated by thermogravimetric analysis (TGA). PANI/Ag/GO and ANL@PANI/Ag/GO were characterized by atomic force microscopy (AFM) and Fourier transform-infrared spectroscopy (FT-IR) in order to determine the coupling between nanosupport and the enzyme. Reusability of the ANL@PANI/Ag/GO has also been evaluated. Moreover, a comparative study of ANL@PANI/Ag/GO and free ANL was executed, and the results showed that the ANL@PANI/Ag/GO has improved catalytic efficiency, thermal and solvent stability than free ANL.

\section{Experimental methods}

\subsection{Chemicals and reagents}

Silver nitrate, graphite flake, glutaraldehyde $25 \%(\mathrm{v} / \mathrm{v})$, bovine serum albumin (BSA) and $p$-nitrophenyl palmitate ( $p$-NPP) were supplied by Sigma-Aldrich (St. Louis, MO, USA). BSA was dialyzed properly against the $20 \mathrm{mM}$ phosphate buffer, $\mathrm{pH}$ 7.4.
Lipase (Aspergillus niger EC 3.1.1.3) was procured from Sisco research laboratories chemicals (Mumbai, India). All the reagents and chemicals used in this study were of analytical grade.

\subsection{Synthesis of PANI/Ag/GO-nanocomposite via in situ polymerization}

In a typical synthesis of PANI/Ag/GO nanocomposites $0.1 \mathrm{M}$ potassium persulphate was added into $10 \%$ solution of aniline in $1: 1$ ratio under constant stirring at low rpm for $3 \mathrm{~h}$. Afterwards, the ammonium persulphate solution was added drop by drop to the aniline solution in $1 \mathrm{M} \mathrm{HCl}$ over a period of $45 \mathrm{~min}$ with continuous stirring. The appearance of dark green colour is an indicator of formation of polyaniline. Now a $2.0 \mathrm{mM}$ of silver nitrate solution prepared in Tris-HCl buffer, $\mathrm{pH} 8.5$ was added drop wise (about 1 drop per second) to the as prepared PANI solution and stirred for $2 \mathrm{~h}$ in an ice bath. Graphene oxide synthesized by means of the oxidative treatment of natural flake graphite (particle size $<150 \mu \mathrm{m}$ ) using a modified Hummers method following ultrasonication treatment ${ }^{24}$ for $1 \mathrm{~h}$ was subsequently added to solution containing PANI/Ag and vigorously stirred in an ice bath for $2 \mathrm{~h}$. The solution was now kept overnight in refrigerator at $4{ }^{\circ} \mathrm{C}$. The product so obtained was washed thrice with double-distilled water, acetone and ethanol and then dried in the hot air incubator at $55 \pm 3{ }^{\circ} \mathrm{C}$ for $20 \mathrm{~h}$.

\subsection{Optimization and immobilization of lipase on PANI/Ag/ GO}

To study the optimization of ANL@PANI/Ag/GO, free lipase (7 U) was independently immobilized on varying concentrations of PANI/Ag/GO nanocomposites (5-20 mg) with variable crosslinker concentrations for different time interval in $50 \mathrm{mM}$ phosphate buffer, pH 7 at $30^{\circ} \mathrm{C}$. Prior to immobilization, lipase powder was purified to the analytical grade by centrifugation. Typically, $100 \mathrm{mg}$ Aspergillus niger lipase was soaked in $100 \mathrm{ml}$ of $50 \mathrm{mM}$ phosphate buffer, $\mathrm{pH} 7$ and centrifuged at $10000 \mathrm{rpm}$ for $15 \mathrm{~min}$, and the sediment granules were discarded. The resulting supernatant comprising of lipase was then stored at $4{ }^{\circ} \mathrm{C}$ for further use.

The immobilized ANL on PANI/Ag/GO (ANL@PANI/Ag/GO) was prepared as follows:

Glutaraldehyde was utilised as the cross-linking agent for the covalent binding of ANL with PANI/Ag/GO. The nanocomposites were ultrasonicated for $30 \mathrm{~min}$ and then used for the immobilization of lipase. For the immobilization procedure, the amino functional groups of support were activated with a given concentration from $25 \%(\mathrm{v} / \mathrm{v})$ glutaraldehyde for different time period from $2-12 \mathrm{~h}$ in the buffer at $4{ }^{\circ} \mathrm{C}$ aimed to obtain maximum yield. The nanosupport was successively activated and then washed thrice with double distilled water to eliminate unbound glutaraldehyde and dried at $60{ }^{\circ} \mathrm{C}$. Typically, soluble lipase $(10 \mathrm{mg}$ ) prepared in $100 \mathrm{ml}$ phosphate buffer, $\mathrm{pH} 7$ was added drop-wisely to a certain amount of PANI/Ag/GO-NCs. After continuous stirring of the mixture $(180 \mathrm{rpm})$ at $4{ }^{\circ} \mathrm{C}$ through a magnetic stirrer for a specified time, the immobilized nanoconjugates were decanted and procured through 
centrifugation. Following centrifugation; the uncross-linked ANL was removed by washing till no protein was detected. The washing solutions were collected and activity assay for lipase was performed in order to detect the amount of uncrosslinked ANL. The immobilized preparation was stored in an assay buffer at $4{ }^{\circ} \mathrm{C}$ for further use.

\subsection{Assay of enzyme activity of free and immobilized ANL}

The lipolytic activity of soluble and immobilized lipase was analysed spectrophotometrically through a UV/Vis JASCO spectrophotometer by evaluating the absorbance at $410 \mathrm{~nm}$ produced by the released $p$-nitrophenol. $p$-NPP was selected as the substrate for the determination of lipase activity. The substrate solution was prepared with $p$-NPP $(150 \mathrm{mM}$ in isopropanol), $150 \mathrm{mg}$ Triton X-100, and $67.5 \mathrm{ml} 25 \mathrm{mM}$ Tris-HCl buffer, pH 7.0. The reaction mixture consisted of $2 \mathrm{ml}$ substrate solution and $0.1 \mathrm{ml}$ lipase solution. The reaction was carried out by incubating the reaction mixture at $37^{\circ} \mathrm{C}$ for $15 \mathrm{~min}$ in a water bath under continuous stirring and afterwards $0.25 \mathrm{ml} 0.1 \mathrm{M}$ $\mathrm{Na}_{2} \mathrm{CO}_{3}$ was added to terminate the reaction. ${ }^{25}$ One unit of lipase activity (U) is defined as the quantity of enzyme that causes the hydrolysis of $1 \mu \mathrm{mol}$ of $p$-nitrophenol from $p$-NPP per min at analysis conditions.

Activity recovery (\%) remaining after the immobilization was the ratio between the activity of immobilized lipase and the activity of the same amount of the soluble lipase in solution that has been immobilized onto PANI/Ag/GO-NPs.

\subsection{Determination of immobilization efficiency}

The immobilization efficiency was calculated in terms of immobilization and activity yields as follows:

$$
\begin{gathered}
\text { Immobilization yield (\%) }=A-B / A \times 100 \% \\
\text { Activity yield }(\%)=C / A \times 100 \%
\end{gathered}
$$

where $A$ is the activity of ANL added in the initial immobilization medium, $B$ is the total activity of the residual lipase in the supernatant and washing solution after the immobilization process, and $C$ is the activity of the immobilized lipase, respectively.

\subsection{Characterization of PANI/Ag/GO and ANL@PANI/Ag/GO}

2.6.1. FT-IR spectroscopy. The interactions of enzyme with NPs were inspected by FT-IR analysis. For FT-IR spectroscopy measurements, the air dried PANI/Ag/GO-NPs were diluted with spectroscopic grade potassium bromide $(\mathrm{KBr})$ in the ratio of $1: 100$. The spectra were recorded in a range of $4000-400 \mathrm{~cm}^{-1}$ with an average of over 12 scans. These measurements were carried out on Perkin Elmer FTIR spectrometer, Spectrum Two (CT, USA).

2.6.2. TGA studies. The TGA was performed using a Perkin Elmer Pyris 1 thermogravimetric analyzer with a $5 \mathrm{mg}$ of sample at a heating rate of $10{ }^{\circ} \mathrm{C} \mathrm{min}^{-1}$ under nitrogen atmosphere.

2.6.3. TEM analysis. Transmission electron microscopy analysis was carried out using JEOL 100/120 kV TEM (JEOL,
Tokyo, Japan) operating at a voltage of $200 \mathrm{keV}$. Samples were prepared by drying $20 \mu \mathrm{l}$ of ultrasonicated PANI/AG/GO-NCs on a copper grid at room temperature.

2.6.4. SEM studies. (a) The surface morphology of the synthesized nanocomposites before and after conjugation with lipase was analysed on JSM 6510LV scanning electron microscope (JEOL, Tokyo, Japan) at an accelerating voltage of $15 \mathrm{kV}$. (b) The elemental analysis of PANI/Ag/GO-NPs was performed using Oxford Instruments INCAx sight EDAX spectrometer equipped SEM.

2.6.5. AFM analysis. The tapping mode AFM experiment of PANI/Ag/GO and ANL@PANI/Ag/GO was utilized to acquire the images using commercial etched silicon tips as an AFM probe (RTESP, Veeco model Icon with controller and Nanoscope 5 integrated system) with typical resonance frequency of $340 \mathrm{~Hz}$ and amplitude $13 \mathrm{mV}$. In order to check the surface uniformity microscopic scans were carried out on several surface locations.

2.6.6. DLS measurements. For size distribution analysis DLS measurements were executed at $830 \mathrm{~nm}$ using DynaPro-TC04 dynamic light scattering equipment (Protein Solutions, Wyatt Technology, Santa Barbara, CA) equipped with a temperature-controlled microsampler. For each experiment, 20 measurements were taken. Mean hydrodynamic radius $\left(R_{\mathrm{h}}\right)$ and polydispersity were analysed using Dynamics 6.10.0.10 software at optimized resolution. The $R_{\mathrm{h}}$ was estimated on the basis of an autocorrelation analysis of scattered light intensity data based on translation diffusion coefficient by Stoke's-Einstein relationship

$$
R_{\mathrm{h}}=\frac{k T}{6 \pi \eta D}
$$

where $R_{\mathrm{h}}$ is the hydrodynamic radius, $k$ is Boltzmann constant, $T$ is temperature, $\eta$ is the viscosity of water and $D$ is diffusion coefficient.

\subsection{Effect of $\mathbf{p H}$}

Enzymatic activity of free and immobilized lipase was evaluated in the buffers of various $\mathrm{pH}$ (4.0-10.0). The buffers used were sodium acetate $(\mathrm{pH} 4.0-5.0)$, sodium phosphate $(6.0,7.0)$ and Tris-HCl (pH 8.0, 9.0) with the molarity of 0.05 M. Effective hydrolysis of $p$-NPP by soluble and immobilized enzyme was monitored at each specific wavelength. The activity at $\mathrm{pH} 7$ and 8 was taken as control $(100 \%)$ for the determination of remaining (\%) activity of free and immobilized enzyme, respectively.

\subsection{Effect of temperature}

The lipolytic activity of free and immobilized lipase was assessed at various temperatures $\left(25-55^{\circ} \mathrm{C}\right)$ in $50 \mathrm{mM}$ sodium phosphate buffer, pH 7 for $10 \mathrm{~min}$. The enzymatic activity at $40{ }^{\circ} \mathrm{C}$ was taken as reference $(100 \%)$ for the calculation of remaining (\%) activity for free and immobilized enzyme.

\subsection{Determination of kinetic parameters}

The enzymatic hydrolysis of $p$-NPP was utilized as the model substrate reaction to determine the kinetic parameters of free ANL 
and ANL@PANI/Ag/GO. The Michaelis-Menten kinetic parameters, $K_{\mathrm{m}}$ and $V_{\max }$, were calculated using variable concentrations (5 to $75 \mathrm{mM}$ ) of $p$-NPP incubated in $50 \mathrm{mM}$ phosphate buffer, $\mathrm{pH} 7$ at optimum temperature. Lineweaver-Burk plots were made in order to calculate the value of $K_{\mathrm{m}}$ and $V_{\mathrm{max}}$.

\subsection{Assessment of operational stability for ANL and ANL@PANI/Ag/GO}

2.10.1. Assessment of ANL temperature stability before and after immobilization. For thermal stability studies, free and immobilized enzyme preparations were simultaneously incubated in $0.05 \mathrm{M}$ sodium phosphate buffer, $\mathrm{pH} 7$ for $2 \mathrm{~h}$ at $60^{\circ} \mathrm{C}$. Specific aliquots of ANL and ANL@PANI/Ag/GO preparations were withdrawn at specified time intervals of incubation and chilled quickly in crushed ice for $5 \mathrm{~min}$. The samples were then brought to room temperature until enzyme assay. The thermal stability of these aliquots of samples was expressed as residual hydrolytic lipase activity after different incubation times with respect to enzyme activity at time zero prior to incubation at $60{ }^{\circ} \mathrm{C}$, considered to be as control $100 \%$.

2.10.2. Storage stability. For the storage stability studies, free lipase and the immobilized nanoconjugates were immersed in $2 \mathrm{ml}$ of $50 \mathrm{mM}$ sodium phosphate buffer, $\mathrm{pH} 7.0$ at $4{ }^{\circ} \mathrm{C}$ and $30{ }^{\circ} \mathrm{C}$ for a period of one month and residual activity was measured at the gap of three days. The storage stability was evaluated by determining the residual enzymatic activity of $p$-NPP hydrolysis, once every three days during 30 days of incubation.

\subsection{Reusability of immobilized enzyme preparation}

Immobilized enzyme (6.2 U) was considered in triplicates for the calculation of the residual enzyme activity in order to inspect its reusability. After each repetitive use, immobilized enzyme was washed with $0.05 \mathrm{M}$ sodium phosphate buffer, $\mathrm{pH}$ 7. The pellet was isolated by centrifugation at $5000 \times g$ for $10 \mathrm{~min}$ and stored in assay buffer at $4{ }^{\circ} \mathrm{C}$. This process was repeated for 11 successive days. The activity determined on the first day was considered as control (100\%) for the calculation of remaining percentage of activity after repetitive uses.

\subsection{Solvent stability}

ANL@PANI/Ag/GO was filtered well and pellets were washed with ethanol and thrice with double distilled water. It was then allowed to be air dried by incubating at $40^{\circ} \mathrm{C}$ for $12 \mathrm{~h}$. Free ANL and ANL@PANI/Ag/GO (1 mg) were incubated in $0.1 \mathrm{ml}$ of various solvents acetone, acetonitrile, isopropanol, butanol, nitroaniline, toluene and chlorobenzene at $30{ }^{\circ} \mathrm{C}$ for $1 \mathrm{~h}$. The biocatalyst incubated in 0.05 sodium phosphate buffer was used as the reference point for the effect of organic solvents. Residual lipase activity after $1 \mathrm{~h}$ with respect to enzyme activity at time zero, considered to be $100 \%$ was evaluated.

\subsection{Estimation of protein concentration}

The concentration of proteins was determined by using the method described by Lowry et al. ${ }^{26}$ Bovine serum albumin was used as a standard protein.

\subsection{Statistical analysis}

The results presented are the mean for three independent experiments performed in triplicates, with average standard deviations of $<5 \%$ and $p$-values of $<0.05$ were considered statistically significant. The data conveyed in these studies was plotted using Origin Plot-8.

\section{Results and discussion}

\subsection{Preparation and optimization of ANL@PANI/Ag/GO}

The optimum preparatory conditions viz; ; cross-linker concentration, cross-linking time and enzyme/nanosupport ratio of ANL@PANI/Ag/GO were assessed timely. The enzyme concentration $\left(1 \mathrm{mg} \mathrm{ml}^{-1}\right)$ was fixed during the preparative condition of ANL@PANI/Ag/GO immobilization. The ratio of enzyme/ nanosupport was varied from $1: 5$ to $1: 20$ and optimum activity recovery was attained at a ratio of $1: 10$ (Fig. 1a). This may be due to the fact that PANI/Ag/GO-NCs favour the strengthening of binding interactions on enzyme and stabilizes its conformation. Whereas, further increasing the nanosupport concentration above the optimum level may lead to an increase in the diffusion limitation and steric hindrance thereby causing a decrease in the recovery of enzymatic activity, ${ }^{27}$ thus inhibiting the reaction catalysis.

The concentration of cross-linking agent was another crucial factor influencing the activity of immobilized enzyme and to observe its effect, different concentrations of glutaraldehyde (1.5-4\%) were varied keeping the enzyme/nanosupport ratio constant. Fig. 1b depicts that the glutaraldehyde concentration of $2.5 \%(\mathrm{v} / \mathrm{v})$ was the most suitable cross-linking parameter. The immobilized enzymatic preparation was excessively crosslinked above the optimum concentration of glutaraldehyde, favouring the inactivation of enzyme due to weakening of enzyme flexibility. While at low concentration it was inadequately cross-linked leading to the release of unbound enzyme into preparatory medium.

When the cross-linking time was extended, a parallel trend was noticed (Fig. 1c). Experiments were conducted by varying the cross-linking time from $2 \mathrm{~h}$ up to $12 \mathrm{~h}$. It was observed that on increasing the coupling time to $4 \mathrm{~h}$, maximum relative catalytic activity was achieved. On the other hand, a declined enzyme activity was detected when the cross-linking time was increased beyond $4 \mathrm{~h}$. This can be explained by the excess covalent binding amongst the amino group of PANI/Ag/GO and the amino group of ANL. Hence, a cross-linking time of $4 \mathrm{~h}$ was most suited for the immobilization of ANL.

As per the results obtained, the highest activity of ANL@PANI/Ag/GO was achieved when the nanosupport/enzyme mass ratio, concentration of the cross-linker and cross-linking time were $10: 1,2.5 \% \mathrm{v} / \mathrm{v}$ and $4 \mathrm{~h}$, respectively.

\subsection{Immobilization efficiency of ANL}

The process of immobilization of lipase on PANI/Ag/GO-NCs was achieved via covalent coupling by glutaraldehyde, a crosslinking agent. Firstly, we determined the optimal contact time for ANL immobilization on PANI/Ag/GO by studying the effect of 

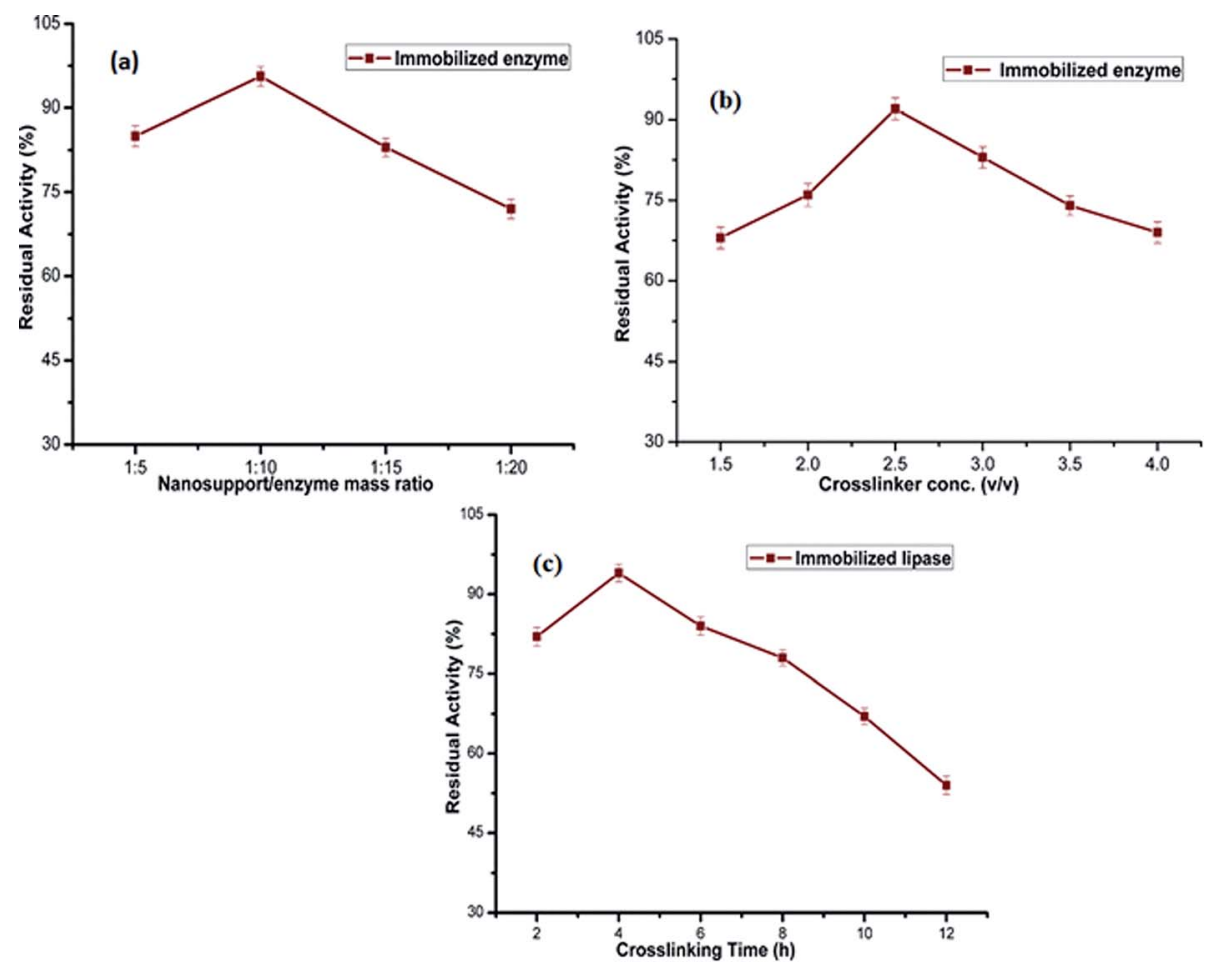

Fig. 1 Effects of immobilization parameters on activity of immobilized lipase. Effect of (a) nanosupport/enzyme mass ratio; (b) effect of crosslinker concentration; (c) effect of crosslinking time.
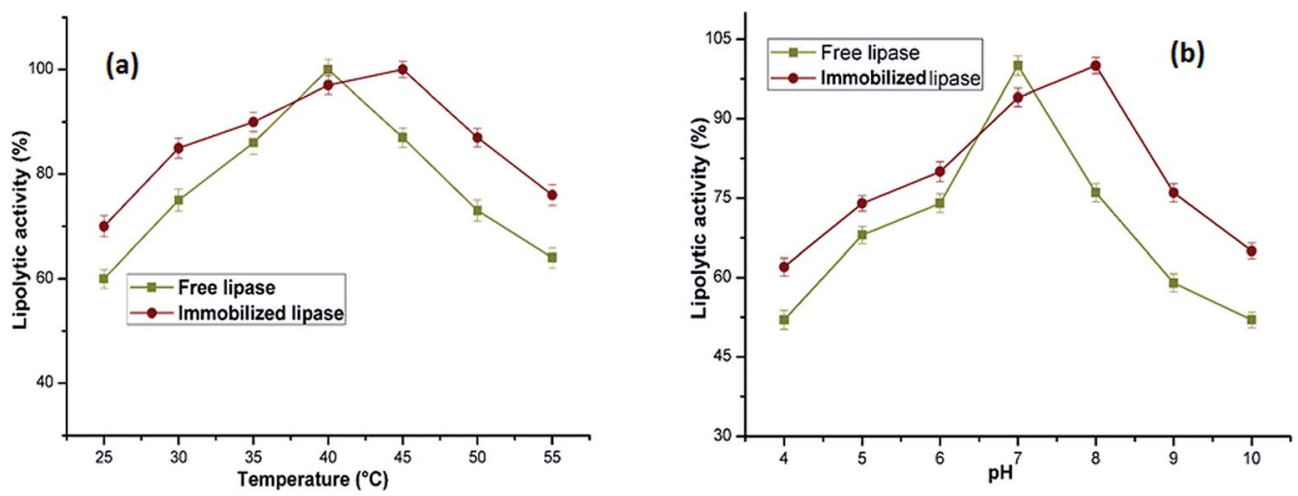

Fig. 2 Temperature-activity profiles (a) for free and immobilized lipase. The lipolytic activity of free and immobilized lipase was determined at various temperatures $\left(25-55^{\circ} \mathrm{C}\right)$ in $0.05 \mathrm{M}$ sodium phosphate buffer, $\mathrm{pH} 7$ for $10 \mathrm{~min}$. The activity obtained at $40{ }^{\circ} \mathrm{C}$ was taken as reference $(100 \%)$ for the calculation of remaining percent activity. Optimal pH activity profiles (b) for free and immobilized lipase. The activity of free and immobilized lipase was assessed in the buffers of varying $\mathrm{pH}(4.0-10.0)$. The molarity of each buffer was $0.05 \mathrm{M}$. The activity at $\mathrm{pH} 7 \mathrm{was}$ taken as control (100\%) for the determination of remaining percent activity. The symbols show (- - -) free and (- -) immobilized lipase.

cross-linking time. In Fig. 1 we have showed the enzyme efficiency obtained at different concentration of cross-linker, nanosupport and the residual activities of the resulting nanoconjugates considering the free ANL activity as control (100\%). The immobilized lipase preparation showed an effectiveness factor $(\eta)$ of 0.94 and activity yield of $88.5 \%$. The effectiveness factor $(\eta)$ value of an immobilized enzyme preparation represents the ratio of actual to theoretical activity of the immobilized enzyme preparation. ${ }^{28}$ Table $\mathrm{S} 1 \dagger$ demonstrates the immobilization efficiency of bound lipase. ANL@PANI/Ag/GO maintained $94 \%$ of its original enzyme activity which was significantly higher in contrast to previous immobilization studies. ${ }^{29}$

\subsection{Optimum temperature and $\mathrm{pH}$ studies}

The optimum temperature of free ANL and ANL@PANI/Ag/GO was also examined at temperatures ranging from $25-55{ }^{\circ} \mathrm{C}$ (Fig. 2a). The free lipase achieves maximum relative activity at an optimum temperature of about $40{ }^{\circ} \mathrm{C}$ and gradual decrease in its catalytic activity is observed at a temperature above it. The biocatalyst ANL@PANI/Ag/GO on the other hand displayed 

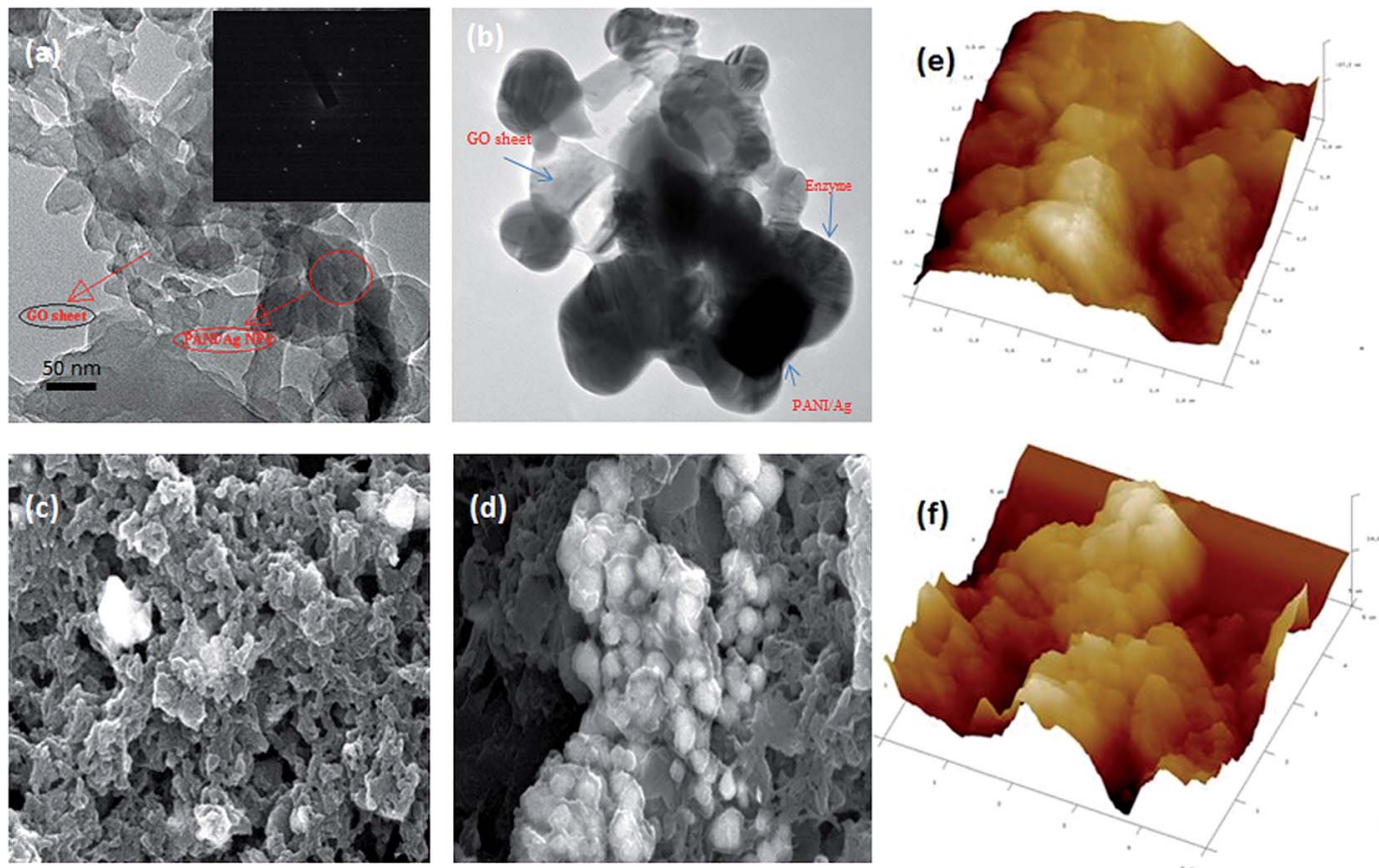

Fig. 3 Transmission electron micrographs of (a) PANI/Ag/GO with the electron diffraction pattern (inset of (a)) and (b) ANL(aPANI/Ag/GO; scanning electron micrographs of (c) PANI/Ag/GO-NPs and (d) ANL(aPANI/Ag/GO; atomic force micrographs of (e) PANI/Ag/GO-NPs and (f) ANL@PANI/Ag/GO. Tapping mode of AFM were perform using commercial etched silicon tips as AFM probes with distinctive resonance frequency of ca. $340 \mathrm{~Hz}$ and $13 \mathrm{mV}$ amplitude (RTESP, Veeco, Japan).


Fig. 4 FT-IR analysis was done to monitor the linkages present between lipase and PANI/Ag/GO nanocomposites. FT-IR spectra of (i) PANI/Ag/ GO, (ii-a) ANL and (ii-b) ANL@PANI/Ag/GO-NC. These measurements were carried out on Perkin Elmer FTIR spectrometer, spectrum two (CT, USA). 
maximum activity at $45{ }^{\circ} \mathrm{C}$ and retained more than $90 \%$ of its relative activity from $35-50{ }^{\circ} \mathrm{C}$. On increasing the temperature to $50{ }^{\circ} \mathrm{C}$, the relative activity of free ANL fell rapidly and achieved $59 \%$ of its relative activity at $55{ }^{\circ} \mathrm{C}$ whereas ANL@PANI/Ag/GO retained approximately $76.5 \%$ of the relative activity at $55{ }^{\circ} \mathrm{C}$. These results showed that ANL had superior heat resistance after immobilization onto the PANI/Ag/GO. Generally, it is accepted that the formation of physical interactions amongst lipase and bionanoconjugate at higher temperatures may inhibit conformational transitions of the enzyme.

The corresponding enzymatic activities of the ANL and ANL@PANI/Ag/GO were investigated under varying $\mathrm{pH}$ ranging from 4.0 and 10.0 in acetate, phosphate, and tris buffers. The purpose was to examine the effect of $\mathrm{pH}$ on the lipolytic activities of the free and immobilized lipase. As visible from the Fig. 2b, at pH 7 and 8 the maximum activities of the free ANL and ANL@PANI/Ag/GO were achieved respectively, with ANL@PANI/Ag/GO showing an increased $\mathrm{pH}$ resistance in the range 7.0-9.0. The shift in the optimum $\mathrm{pH}$ for the prepared ANL@PANI/Ag/GO compliments the previous literature which indicated comparable results after immobilization. ${ }^{30}$ This may possibly be due to the strong interactions amongst the lipase and the support, including electrostatic interactions ${ }^{31}$ as well as hydrogen bonding. ${ }^{32,33}$ It is worth mentioning that the ANL@PANI/Ag/GO displayed a higher sensitivity towards alkaline region as compared to free ANL. To be precise, at $\mathrm{pH} 9$, the ANL@PANI/Ag/GO retained $75.9 \%$ of lipolytic activity, whereas that of its soluble counterpart was only $56.8 \%$. This result specifies that the ANL immobilized on the ANL@PANI/Ag/GONCs possesses better adaptability to $\mathrm{pH}$ which can have a profound effect on the applications of lipase in biocatalytic and chemical industry.

\subsection{Characterization}

The morphology of the nanoparticles before and after conjugation with enzyme was visualized by TEM analysis. Obtained electron micrographs support the successful immobilization of lipase with PANI/Ag/GO-NCs. The TEM image of PANI/Ag/GO nanospheres at a magnification of $50000 \times$ (Fig. 3a) clearly depicts that the nanospheres are solid and spherical in shape with the average particle size $50 \mathrm{~nm}$. The TEM images corroborate the ability of GO nanosheets to attach with Ag-NPs on their surface. In addition, characteristic selected area electron diffraction (SAED) pattern of the NCs (inset of Fig. 3a) exhibits multiple-crystal diffraction features which matches very well with the previous report. ${ }^{34}$ The Fig. $3 \mathrm{~b}$ shows the conjugation of lipase to PANI/Ag/GO-NCs. The NCs remain spherical after binding of enzyme but the mean diameter increased from 50 to $72 \mathrm{~nm}$ dispersed uniformly with certain aggregation due overlapping of some smaller particles with the bigger ones. It demonstrates the binding of a substantial amount of enzyme on the NPs surface suggesting that the conjugation process did not alter the morphology of the NPs while the size has increased. The surface morphology of the samples was examined by SEM. SEM data in Fig. 3c revealed the surface of GO sheets was modified by the nanosized Ag-NPs. Most of the synthesized Ag-
NPs adsorbed on the GO exhibit spherical shape, which displays a good combination between Ag-NPs and GO with large surfaces available for the conjugation of a significant amount of enzyme. After immobilization, the surface morphology of the corresponding scanning electron micrograph as visible from the Fig. 3d was remarkably changed since the whole surface of the nanosupport is covered with enzyme without hindering its activity profile. The tapping mode in AFM was utilized to analyse the peak to peak valley distance in microphotographs as an indicator for roughness of the surface. The surface roughness in these images can be interrelated to the pattern of immobilization. As visible from Fig. 3e, the NPs surface is comparatively smooth and has lesser peak-to-valley distance. Once an enzyme molecule is conjugated (Fig. 3f), there was a substantial increase in peak-to-valley distance which indicates high enzyme loading as a result of casing of NPs surface by the enzymes.

FT-IR analysis was performed, to investigate the presence of characteristic functional groups. In this study, FTIR analysis was used to examine the characteristic functional group of synthesized nanocomposite (Fig. 4i), free lipase (Fig. 4ii-a) and lipase immobilized on PANI/Ag/GO-NCs (Fig. 4ii-b). The FT-IR spectra of nanocomposite contains signal in the wavenumber range $1085,1440,1580$ and $3425 \mathrm{~cm}^{-1}$. The peak at $1580 \mathrm{~cm}^{-1}$ corresponds to a stretching vibration from $\mathrm{C}=\mathrm{C}$ bonds and at $1085 \mathrm{~cm}^{-1}$ from $\mathrm{C}-\mathrm{O}$ bonds agreeing to the remaining $\mathrm{sp}^{2}$ character and alkoxy/epoxy group respectively. ${ }^{35}$ The peak at $3425 \mathrm{~cm}^{-1}$ points to the oxygenated functional groups $-\mathrm{OH}$ indicating GO had a certain amount of adsorbed water. Particularly, the PANI/Ag/GO nanocomposite shows a first-hand peak at $1440 \mathrm{~cm}^{-1}$, resultant from the $\mathrm{C}-\mathrm{N}$ stretching vibration of slightly reduced $\mathrm{Ag}-\mathrm{GO}$ during the synthesis of the PANI/Ag/GO nanocomposite. The FT-IR spectrum of Aspergillus niger lipase shows dominant peaks in the wavenumber range 3420-3150 $\mathrm{cm}^{-1}$ (-OH stretching vibrations and $-\mathrm{NH}$ stretching vibrations), at $2924 \mathrm{~cm}^{-1}$ (C-H stretching vibrations), $1652 \mathrm{~cm}^{-1}(\mathrm{~N}-$ $\mathrm{H}$ bending vibrations) and $1080 \mathrm{~cm}^{-1}$ (C-O bond stretching vibrations). The FTIR spectrum of the immobilized lipase confirmed the presence of a number of functional groups in the enzyme structure which must be involved in the covalent binding of the enzyme with cross-linker glutaraldehyde to PANI/ Ag/GO-NCs. The peaks at 3485 and $2920 \mathrm{~cm}^{-1}$ correspond to linkage of the free $\mathrm{COO}^{-}$group of lipase with the $\mathrm{NH}_{2}$ group of PANI (Fig. 4ii-b). There is a substantial increase on intensity of peaks at $3485,2920,1648$, and $1148 \mathrm{~cm}^{-1}$, which point to the successful immobilization of the ANL. ${ }^{36}$ These changes might be associated to the formation of chemical bonds with nitrogen and oxygen, signifying that $-\mathrm{OH}$ and $-\mathrm{NH}$ were involved in the reaction with glutaraldehyde and conjugation was successfully established between lipase and PANI/Ag/GO-NPs.

Dynamic light scattering measurements were employed to examine the size and polydispersity of PANI/Ag/GO-NPs and ANL@PANI/Ag/GO-NCs. The hydrodynamic radii $\left(R_{\mathrm{h}}\right)$ and percent polydispersity of free nanocomposites were $62 \mathrm{~nm}$ and $24.5 \%$, respectively (Fig. 5a). These values were increased considerably after conjugation with lipase. The hydrodynamic radii $\left(R_{\mathrm{h}}\right)$ and percent polydispersity were $100 \mathrm{~nm}$ and $32.6 \%$, respectively and this might be due to the aggregation of bigger 


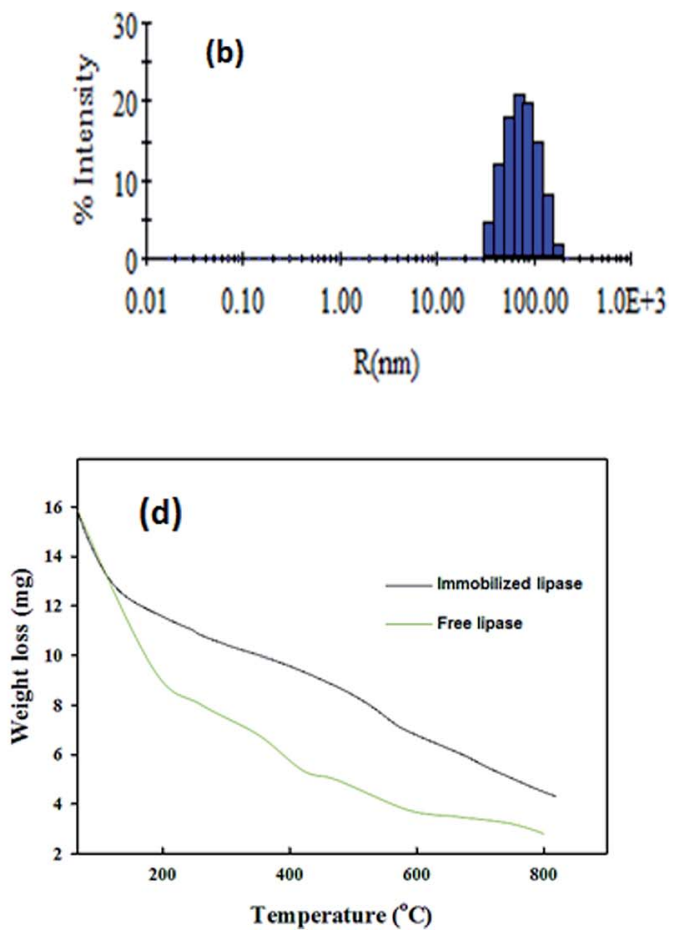

Fig. 5 The DLS measurements showing hydrodynamic size distribution of (a) PANI/Ag/GO nanocomposites and (b) ANL@PANI/Ag/GO. (c) EDX analysis and (d) TGA analysis of ANL(aPANI/Ag/GO and free lipase.

particles with the smaller particles (Fig. 5b). The presence of each element in PANI/Ag/GO-NPs samples was examined by using EDAX. EDX elemental mapping is also used to probe the elemental distribution and structure of the nanocomposites. ${ }^{37}$ As an illustrative example, the elemental mappings of C, Ag, O, $\mathrm{N}_{2}$, Si and the EDX spectrum was taken from similar area for PANI/Ag/GO sample (Fig. 5c). It can be evidently seen that graphene, as a support or background material, is covered by $\mathrm{Ag}$ with some Ag rich phase regions due to the successful surface coating of Ag NPs which compliments well with the TEM result. The nanocomposite was prepared on the silica cover slip for SEM analysis and thus the corresponding peak for Si was seen. The nitrogen peak corresponds for the amino group of polyaniline. The thermal behaviour of prepared PANI/Ag/GO bioconjugate and free enzyme was studied by TGA analysis. The TGA profile of ANL@PANI/Ag/GO-NCs shows three major weight loss steps. Compared to the immobilized lipase preparation, free ANL showed faster decomposition which could be accredited to denaturation of proteinaceous linked lipase structure. The weight loss onset around $300{ }^{\circ} \mathrm{C}$ indicates the structural decomposition of PANI (Fig. 5d). Thus, the results in Fig. $5 \mathrm{~d}$ indicate that the nanoconjugate is thermally more stable than free form of enzyme. The gradual weight loss over the wide temperature range could be attributed to good thermal stability of the PANI/Ag nanospheres.

\subsection{Kinetic parameters}

An investigation of Michaelis-Menten kinetics was carried out with variable substrate concentrations. The Michaelis-Menten constant $\left(K_{\mathrm{m}}\right)$ and the maximum reaction velocity $\left(V_{\max }\right)$ values for free and immobilized lipase were calculated according to the Lineweaver-Burk plots. $K_{\mathrm{m}}$ is associated to the affinity between enzyme and its substrate. A higher value of $K_{\mathrm{m}}$ means less affinity between the enzyme and substrate while lower values of $K_{\mathrm{m}}$ mean higher affinity between them. As viewed from the Table 1, the apparent $K_{\mathrm{m}}$ value for ANL@PANI/Ag/GO $(15.8 \mathrm{mM})$ which was much lesser than that for free lipase $(28.70 \mathrm{mM})$, specifies that ANL@PANI/Ag/GO attached to the substrate more easily and had reasonably high catalytic efficiency. This result is similar to the work reported previously, which suggest that it could be owing to more effective conformation of immobilized lipase, or due to enzyme expanding on the surface of the NPs with a superior orientation leading to more accessible active sites and improved affinity to substrate..$^{38,39}$

$V_{\max }$ theoretically represents the maximum rate achieved by the system. The $V_{\max }$ value for ANL@PANI/Ag/GO was lower than that for ANL. This could be ascribed to the partial inactivation of enzyme, diffusional limitations, steric hindrances or structural changes happening in enzyme after the covalent coupling with the cross-linker which, in turn improved the thermal stability of the immobilized preparation. ${ }^{40}$

Table 1 Apparent kinetics parameters of free ANL and ANL@PANI/Ag/ GO-NC

\begin{tabular}{llll}
\hline Enzymatic preparation & $K_{\mathrm{m}}\left(\mathrm{mM} \mathrm{min}^{-1}\right)$ & $V_{\max }$ & $V_{\max } / K_{\mathrm{m}}\left(\mathrm{min}^{-1}\right)$ \\
\hline ANL & 28.7 & 9.4 & 0.32 \\
ANL@PANI/Ag/GO-NC & 15.8 & 6.2 & 0.39
\end{tabular}


Furthermore, the $V_{\max } / K_{\mathrm{m}}$ value for ANL@PANI/Ag/GO was higher than the corresponding value for free ANL (0.39 vs. 0.32 $\mathrm{min}^{-1}$ ), indicating that ANL@PANI/Ag/GO attached to the substrate with ease and had reasonably high catalytic efficiency.

\subsection{Storage stability}

To investigate the storage stability of free and immobilized ANL, both aliquots were stored at temperatures $4{ }^{\circ} \mathrm{C}$ and $30^{\circ} \mathrm{C}$. Fig. $6 \mathrm{a}$ shows the effect of storage time at both the temperatures on the activity of the free and immobilized ANL. The results reveal that the enzymatic preparation following immobilization showed superior retention of its initial hydrolytic activity irrespective of the storage temperature. The maximum catalytic activity is that of immobilized lipase stored at $4{ }^{\circ} \mathrm{C}$, which maintained $88 \%$ of its initial activity after 30 days of storage, while the highest decrease in activity, about $65 \%$ of the initial activity, was recorded for the free enzyme stored at $30^{\circ} \mathrm{C}$ for 30 days. This could be explained by alteration of the three dimensional structure of the enzyme as immobilization leads to increase rigidity of the enzyme to the nanoparticles. ${ }^{41}$ Moreover, these results demonstrate that immobilization helps to retain the catalytic activity of the ANL and stabilizes the confirmation of the enzyme.

\subsection{Thermal stability}

Fig. 6b depicts the thermal stability profiles for soluble and immobilized ANL. The free ANL lost $51 \%$ of its catalytic activity after $2 \mathrm{~h}$ at $60{ }^{\circ} \mathrm{C}$, while ANL@PANI/Ag/GO complex exhibited remarkable $85 \%$ activity retention under similar incubation conditions. This is in accordance to the recently published report which shows the thermal stability of the immobilized lipase was higher than the free form. ${ }^{42}$

\subsection{Solvent stability}

As illustrated in Fig. 6c, seven solvents were used to investigate the organic solvent tolerance of both free ANL and ANL@PANI/ $\mathrm{Ag} / \mathrm{GO}$ after $1 \mathrm{~h}$ of incubation. ANL@PANI/Ag/GO displayed better solvent tolerance to these seven solvents rather than its free counterpart. Isopropanol exhibited the lowest toxicity to free ANL, while the simplest ketone (acetone) showed the lowest toxicity to ANL@PANI/Ag/GO as its residual activity was high $(81.5 \%)$ and was almost double than that of free ACL (40\%). Similarly, $1 \mathrm{~h}$ incubation with toluene caused nearly $75 \%$ loss of activity in free ANL, but the ANL@PANI/Ag/GO maintained 55\% of its initial activity. Overall in contrast with the free counterpart, the ANL-immobilized on PANI/Ag/GO-NCs had higher


Fig. 6 Stability of free ANL and ANL@PANI/Ag/GO. (a) Storage stability at $4{ }^{\circ} \mathrm{C}$ and $30{ }^{\circ} \mathrm{C}$; (b) thermal denaturation; (c) solvent stability. 


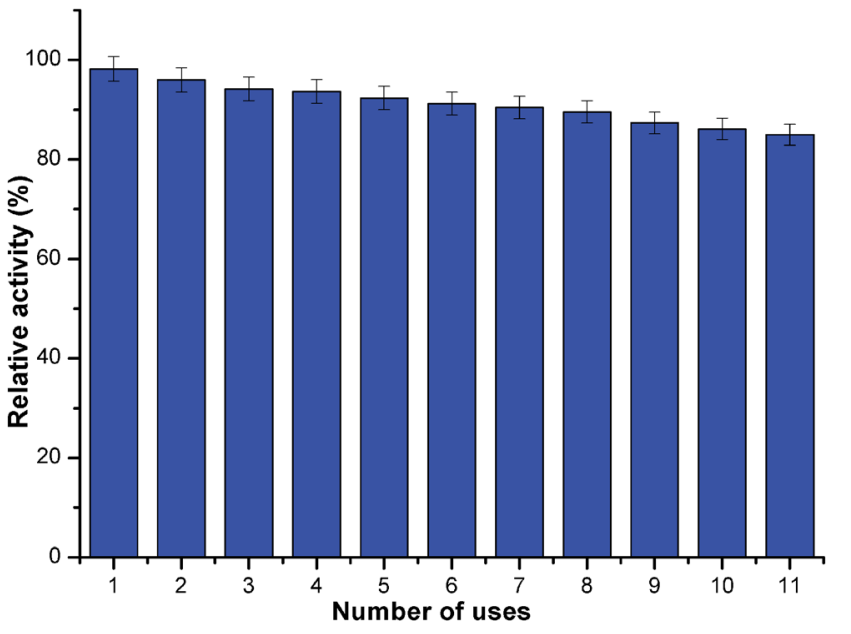

Fig. 7 Reusability assay of immobilized lipase. The biocatalyst was easily separated through low speed centrifugation and the reusability of immobilized preparation was monitored for 11 successive days. The activity determined on the first day was taken as the control (100\%) for the calculation of the remaining percentage activity after each use.

inactivation resistance to these seven solvents. In previous reports, similar improved solvent stability as well as maintenance of catalytic activity with immobilized enzyme preparation have been noticed. Commonly the exposure to organic solvents or ionic liquids cause the stripping of water from the protein surface, along with solvent penetration into the enzyme, leading to protein unfolding and rapid deactivation of the enzyme. However, after the immobilization of ANL on PANI/Ag/GO-NCs, organic solvents do not easily strip off the water layer from the surface of the enzyme thus maintaining the inner rigidity of the ANL and its catalytic conformation significantly. ${ }^{43}$ As the catalytic performance of lipases is reliant onto their tolerance to different solvent systems, the finding that our ANL@PANI/Ag/ GO-NCs showed remarkably high stability in most of the solvents proposes its potential as a nanobiocatalyst for transesterification reactions and biodiesel production.

\subsection{Reusability of immobilized enzyme}

High cost of enzymes used for industrial purposes and the time necessary for their immobilization for subsequent use has led to increase the possibility of reusing immobilized enzyme. Enzyme reuse provides a number of cost advantages that are often an essential prerequisite for establishing an economically viable enzyme catalyzed process. ANL@PANI/Ag/GO retained nearly $85 \%$ activity after its $11^{\text {th }}$ repeated use (Fig. 7). The gradual but slight decrease in enzyme activity could be due to loss of enzyme activity during centrifugation after each use. Thus, its excellent reusability provides a cost-effective advantage for its exploitation in an economically viable enzyme catalyzed process for industrial applications.

\section{Conclusion}

The present approach of synthesising polyaniline modified silver graphene oxide supports may be extended for fabricating other NP-containing composite and nanofibrous materials for various applications in catalysis, sensing, biomedical sciences and industries. We have showed that lipase immobilized on $\mathrm{PANI} / \mathrm{Ag} / \mathrm{GO}$ retains its activity at high temperatures when compared to free, non-immobilized enzyme ( $84 \%$ of its activity recovery vs. $49 \%$ of activity recovery at $60{ }^{\circ} \mathrm{C}$ ). The resulting ANL@PANI/Ag/GO-NCs had enhanced $\mathrm{pH}$ and temperature adaptation, higher activity and stronger storage stability, and enhanced solvent tolerance in contrast with its free counterpart. This has very significant implications to the use of this enzymatic preparation for bio-industries. Apparently, the asprepared immobilized nanobiocatalysts are promising and versatile candidates having great potential in biotechnological processes for biocatalytic reactions.

\section{Conflict of interest}

The authors declare that there is no conflict of interest.

\section{Abbreviations}

\begin{tabular}{|c|c|}
\hline GO & graphene oxide \\
\hline PANI & Polyaniline \\
\hline $\mathrm{PANI} / \mathrm{Ag} / \mathrm{GO}$ & $\begin{array}{l}\text { Polyaniline-silver functionalized graphene } \\
\text { oxide nanocomposites }\end{array}$ \\
\hline ANL & Aspergillus niger lipase \\
\hline $\begin{array}{l}\text { ANL@PANI/Ag/ } \\
\text { GO }\end{array}$ & Immobilized lipase \\
\hline NCs & Nanocomposites \\
\hline NPs & Nanoparticles \\
\hline$p$-NPP & $p$-Nitrophenyl palmitate \\
\hline SEM & Scanning electron microscopy \\
\hline TEM & Transmission electron microscopy \\
\hline AFM & Atomic-force microscopy \\
\hline TGA & Thermogravimetric analysis \\
\hline FT-IR & Fourier transform infrared spectroscopy \\
\hline DLS & Dynamic light scattering \\
\hline
\end{tabular}

\section{Acknowledgements}

Shamoon Asmat acknowledges USIF, AMU for providing the facilities of TEM and SEM. AFM was performed in IIT Kanpur instrumentation facility. Department of Applied Physics, AMU is duly acknowledged for providing TGA.

\section{References}

1 C. Garcia Galan, A. Berenguer Murcia, R. FernandezLafuente and R. C. Rodrigues, Adv. Synth. Catal., 2011, 353, 2885-2904.

2 M. J. Khan, Q. Husain and A. Azam, Biotechnol. Bioprocess Eng., 2012, 17, 377-384.

3 S. Ansari and Q. Husain, Pol. J. Chem. Technol., 2011, 13, 1520.

4 M. d. P. G. Torres, M. L. Foresti and M. L. n. Ferreira, $A M B$ Express, 2013, 3, 1. 
5 S. A. Ansari and Q. Husain, Biotechnol. Adv., 2012, 30, 512523.

6 Q. Husain, Crit. Rev. Biotechnol., 2010, 30, 41-62.

7 A. A. Babadi, S. Bagheri and S. B. A. Hamid, Biosens. Bioelectron., 2016, 79, 850-860.

8 A. Manrich, A. Komesu, W. S. Adriano, P. W. Tardioli and R. L. C. Giordano, Appl. Biochem. Biotechnol., 2010, 161, 455-467.

9 L. Soler, A. s. Illanes and L. Wilson, Catal. Today, 2016, 259, 177-182.

10 X. Zhao, F. Qi, C. Yuan, W. Du and D. Liu, Renewable Sustainable Energy Rev., 2015, 44, 182-197.

11 S. H. Duarte, G. L. z. del Peso Hernandez, A. Canet, M. D. Benaiges, F. Maugeri and F. Valero, Bioresour. Technol., 2015, 183, 175-180.

12 N. Gurung, S. Ray, S. Bose and V. Rai, BioMed Res. Int., 2013, 2013, 329121.

13 T. Momsia and P. Momsia, Int. J. Life Sci. Biotechnol. Pharma Res., 2013, 2, 1-16.

14 M. J. Khan, Q. Husain and S. A. Ansari, Appl. Microbiol. Biotechnol., 2013, 97, 1513-1522.

15 S. Mahouche-Chergui, M. Guerrouache, B. Carbonnier and M. M. Chehimi, Colloids Surf., A, 2013, 439, 43-68.

16 S. A. Ansari and Q. Husain, J. Mol. Catal. B: Enzym., 2011, 70, 119-126.

17 Y. Chen, Q.-L. Zhu, N. Tsumori and Q. Xu, J. Am. Chem. Soc., 2015, 137, 106-109.

18 M. Khan, Q. Husain and A. H. Naqvi, RSC Adv., 2016, 6, 53493-53503.

19 M. L. t. Yola, T. Eren and N. Atar, Electrochim. Acta, 2014, 125, 38-47.

20 P. T. Yin, S. Shah, M. Chhowalla and K.-B. Lee, Chem. Rev., 2015, 115, 2483-2531.

21 S. Palanisamy, C. Karuppiah and S.-M. Chen, Colloids Surf., B, 2014, 114, 164-169.

22 Y. Wu, W. Xu, Y. Wang, Y. Yuan and R. Yuan, Electrochim. Acta, 2013, 88, 135-140.

23 P. Ma, H. Zhu, J. Wei and M. Zhang, Nanosci. Nanotechnol. Lett., 2015, 7, 127-133.

24 Z. Ji, X. Shen, M. Li, H. Zhou, G. Zhu and K. Chen, Nanotechnology, 2013, 24, 115603.
25 I. Deveci, Y. I. DoÄŸaÃ§, M. Teke and B. Mercimek, Appl. Biochem. Biotechnol., 2015, 175, 1052-1068.

26 O. H. Lowry, N. J. Rosebrough, A. L. Farr and R. J. Randall, J. Biol. Chem., 1951, 193, 265-275.

27 G. M. Qiu, B. K. Zhu and Y. Y. Xu, J. Appl. Polym. Sci., 2005, 95, 328-335.

28 S. A. Ansari and Q. Husain, J. Mol. Catal. B: Enzym., 2010, 63, 68-74.

29 W. Xie and N. Ma, Energy Fuels, 2009, 23, 1347-1353.

30 L. Cao, F. van Rantwijk and R. A. Sheldon, Org. Lett., 2000, 2, 1361-1364.

31 R. C. Rodrigues, Ã. n. Berenguerâ€ Murcia and R. Fernandezâ€ Lafuente, Adv. Synth. Catal., 2011, 353, 2216-2238.

32 J. Jordan, C. S. S. R. Kumar and C. Theegala, J. Mol. Catal. B: Enzym., 2011, 68, 139-146.

33 Q. D. Nguyen, J. M. Rezessy-Szabo, B. l. Czukor and A. Hoschke, Process Biochem., 2011, 46, 298-303.

34 Q. Bao, D. Zhang and P. Qi, J. Colloid Interface Sci., 2011, 360, 463-470.

35 D. Chen, H. Feng and J. Li, Chem. Rev., 2012, 112, 6027-6053. 36 R. Yadav, N. Labhsetwar, S. Kotwal and S. Rayalu, J. Nanopart. Res., 2011, 13, 263-271.

37 K. M. Gregorio-Jauregui, M. G. Pineda, J. E. Rivera-Salinas, G. Hurtado, H. Saade, J. L. Martinez, A. Ilyina and R. 1. G. Lopez, J. Nanomater., 2012, 2012, 4.

38 A. Kilara, K. M. Shahani and F. W. Wagner, Biotechnol. Bioeng., 1977, 19, 1703-1714.

39 E. Ranjbakhsh, A. K. Bordbar, M. Abbasi, A. R. Khosropour and E. Shams, Chem. Eng. J., 2012, 179, 272-276.

40 N. Z. Prlainovic, Z. D. Knezevic-Jugovic, D. Z. Mijin and D. I. Bezbradica, Bioprocess Biosyst. Eng., 2011, 34, 803-810.

41 E. Yilmaz, K. Can, M. Sezgin and M. Yilmaz, Bioresour. Technol., 2011, 102, 499-506.

42 S. C. Lau, H. N. Lim, M. Basri, H. R. F. Masoumi, A. A. Tajudin, N. M. Huang, A. Pandikumar, C. H. Chia and Y. Andou, PLoS One, 2014, 9, e104695.

43 C. M. Romero, L. M. Pera, F. Loto, C. Vallejos, G. Castro and M. D. Baigori, Biocatal. Agric. Biotechnol., 2012, 1, 25-31. 